\title{
THE DEPENDENCE OF SUSPENDED SAND CONCENTRATION ON THE DEGREE OF STORM DEVELOPMENT
}

\author{
Kos’yan R. ${ }^{\text {, Grüne J. }}{ }^{2}$, Divinskiy B. ${ }^{1}$, Podymov I. ${ }^{1}$, Vincent C. ${ }^{3}$, Ahmari A. ${ }^{2}$, Oumeraci H. ${ }^{2}$ \\ The basic purpose of the present research is the establishment of connections between surface waves' spectral \\ characteristics and laws of the bottom material suspension. The basic method is the laboratory experiment that allows \\ controlling the interconnected dynamic parameters of the water environment and processes of bottom deposits \\ transport. It is shown, that observed suspension laws physical preconditions are the nonlinear intrawave interactions \\ and hence the redistribution of waves spectral energy in frequency area.
}

Keywords: laboratory experiment; Large Wave Channel; wave spectra; JONSWAP; suspended sediment concentration; wave-wave interactions

\section{INTRODUCTION}

In traditional models only the time averaged characteristics of water circulation, sediment and pollutant transport processes are considered. Sometimes the group structure of waves, their transformation within the coastal zone, the contribution of phase shift between sediments and the fluid at different frequencies of an irregular wave spectrum are taken into account. The influence of the surface wave spectra form, however, has never been considered. First results of the possibility of such dependence were given in the article (Grüne et al 2007), where it was shown that the form of wave spectrum could greatly influence on the suspended sediment concentration (SSC) values. With the same wave height and period $\left(\mathrm{H}_{\text {sig }}\right.$ and $\left.\mathrm{T}_{\mathrm{p}}\right)$ the spectral shape can alter the concentration by 2.5 times.

Therefore, in 2008 the new large-scale laboratory experiments ("Hannover-2008") were performed in the LARGE WAVE CHANNEL (GWK) of the Coastal Research Centre (FZK) in Hannover. One of the tasks of these experiments was the study of the suspended sand concentration dependence under irregular waves with various spectra forms. Simultaneous measurements of SSC, free surface elevations and two-component velocities (including turbulent fluctuations) were carried out at several levels above the sea bed.

\section{EXPERIMENTS DESCRIPTION}

When physically simulating dynamic processes in the coastal zone at prototype scale it is extremely important to keep the similarity of both hydrodynamic and lithodynamic processes. The LARGE WAVE CHANNEL (GWK) of the Coastal Research Centre (FZK) in Hannover has a total length of $303 \mathrm{~m}$, a width of $5 \mathrm{~m}$, a total depth of $7 \mathrm{~m}$ and the maximum water depth of $5 \mathrm{~m}$. For the experiments described here a sand bed was installed. The wave generator is absorption controlled and allows waves of up to $2 \mathrm{~m}$ depending of the local water depth along the channel.

The following devices were used in implementation of this research: optical turbidimeters (4 pieces) and acoustic backscattering systems (ABS) (vertical profilers -2 pieces) for the measurement of suspended sediment concentration; two 2-component electro-magnetic gauges of current velocity «Type "NSW"» ( 2 pieces); string wavemeters ( 25 pieces); sediment pumping system (TSS) with 5 tubes for measurement of averaged suspended sediment concentration at 5 horizons. The installed measuring equipment is shown at Figure 1.

Data were recorded on a PC aided by the parallel multi-channels analog-to-digital converters (ADC) with the frequency of $40 \mathrm{~Hz}$. Information from every parameter was recorded synchronously into a single file. This regime of parallel (simultaneous) recording guaranteed strict synchronicity of all measured parameters.

One task of the experiment was to receive data series of suspended sediment concentration fluctuations measured with different methods. The measurements were performed with different instruments under various wave regimes in which wave parameters and wave steepness changed consecutively. Wave regimes were set by the wave generator controlling program. During the experiment 33 special tests were done. For each test series the peak period was kept constant $\left(T_{p}=5 \mathrm{~s}\right)$ while the significant wave height and spectral steepness were changed consecutively $\left(\mathrm{H}_{\text {sig }}=0.8\right.$ to $1.2 \mathrm{~m}$, wave spectrum steepness index $\gamma=1.0$ to 10.0 ). We presumed that when keeping the $T_{p}$ and $\mathrm{H}_{\text {sig }}$ constant the total energy of the waves remains constant.

\footnotetext{
${ }^{1}$ The Southern Branch of the P.P. Shirshov Institute of Oceanology, RAS, Gelendzhik, Russia

${ }_{3}^{2}$ Coastal Research Centre FZK, Hannover, Germany

${ }^{3}$ School of Environmental Sciences, University of East Anglia, Norwich, U.K.
} 

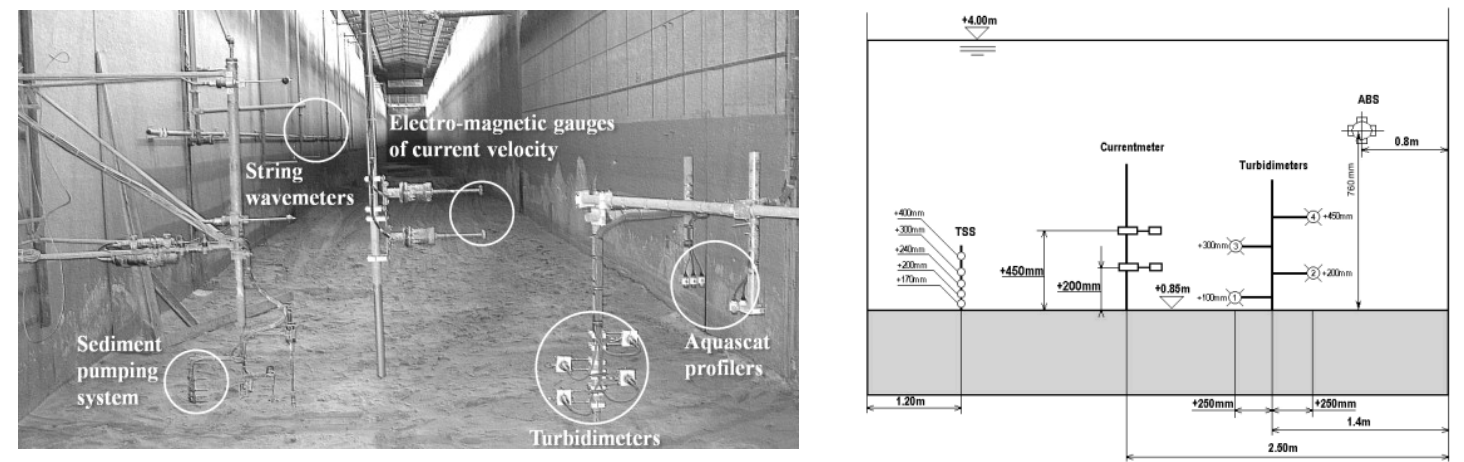

Figure 1. The scheme of the equipment installation in the GWK during experiment.

Wave spectra, generated by the channel wave generator, were assigned by corresponding JONSWAP spectra with a set of parameters, namely: a significant wave height being $\mathrm{H}_{\mathrm{m} 0}=0.8,1.0,1.2$ $\mathrm{m}$, peak of period being $\mathrm{T}_{\mathrm{p}}=5 \mathrm{sec}$, wave spectrum steepness parameter being $\gamma=1.0 \ldots 9.9$. JONSWAP spectra are commonly used in engineering practice and scientific calculations.

JONSWAP project (Joint North Sea Wave Project) was realized in 1967 by the efforts of specialists from Germany, Holland, USA and Great Britain (Hasselmann et al., 1973). Goals of the project were investigations of patterns of wave growth in conditions of limited fetch, and processes of wave field transformation when wave is passing from deep water to the shallow one. Instantaneous measurements of wave and wind parameters were fulfilled along the line stretching to the west from Sylt Island (Sylt, Germany) for more than $160 \mathrm{~km}$. After the processing of a large number of experimental wave spectra, which correspond to the western winds of different intensity, a form of spectral density recording of developing wind waves (in contrast to Pirson-Moscowits spectrum for completely developed spectrum) was suggested. It was called JONSWAP spectra:

$$
S(f)=\frac{\alpha g^{2}}{(2 \pi)^{4}} f^{-5} \exp \left(-\frac{5}{4}\left(\frac{f}{f_{m}}\right)^{-4}\right) \gamma^{\exp \left(-\frac{1}{2 \sigma^{2}}\left(\frac{f}{f_{m}}-1\right)^{2}\right)} .
$$

Parameterized form of spectrum can be described as:

$$
S(f)=\alpha H_{m 0}^{2} f_{m}^{4} f^{-5} \exp \left(-\frac{5}{4}\left(\frac{f}{f_{m}}\right)^{-4}\right) \gamma^{\exp \left(-\frac{1}{2 \sigma^{2}}\left(\frac{f}{f_{m}}-1\right)^{2}\right)}
$$

Here:

$$
\begin{aligned}
& \alpha \approx \frac{0.0624}{0.230+0.0336 \gamma-\left(\frac{0.185}{1.9+\gamma}\right)}, \\
& \sigma \approx 0.07 f \leq f_{m}, \\
& \sigma \approx 0.09 f>f_{m}, \\
& \gamma \text { - peak enhancement coefficient. }
\end{aligned}
$$

Thus, JONSWAP spectrum is determined by three parameters: considerable wave height $H_{m 0}$, period of spectrum peak $f_{m}$ and parameter $\gamma$, which controls the peak form sharpness.

Spectral moments are presented as $M_{n}=\int f^{n} S(f) d f, \mathrm{n}=0,1,2 \ldots$ When distribution of wave height is Rayleigh, the significant wave height is determined as $H_{m 0}=4 \sqrt{M_{0}}$. Thus, a zero moment of spectrum, which is an area under a curve of spectral density, calls for a significant wave height. Sharpness of wave spectrum may be described by spectral bandwidth $\varepsilon=\sqrt{1-\frac{M_{2}^{2}}{M_{0} M_{4}}}$. For narrow band spectrum $\varepsilon \rightarrow 0$. $\varepsilon$ value, found from wave power spectrum, is not steady enough index of spectral bandwidth owing to the influence of high-frequency noise upon the accuracy of determination of $M_{2}$ and $M_{4}$ moments. In 1974 Goda suggested spectral steepness parameter: 


$$
Q_{p}=\frac{2}{M_{0}^{2}} \int_{0}^{\infty} f S^{2}(f) d f
$$

which in this case depends only on a zero moment of spectrum and does not correlate directly with $\varepsilon$. On the whole, a small value of $\varepsilon$ assumes a large value of $Q_{p}$ and vice versa.

Wave spectrum characteristics are given in Fig. 2 and 3.

In any case transformation of input spectrum of irregular waves into the commands of wave generator is connected with the signal distortion. And then several procedures are fulfilled (Liu, Frigaard, 2001):

-JONSWAP spectrum with adjusted input parameters is determined;

-the spectrum is divided into $\mathrm{N}$ parts, and $\mathrm{N}$ determines a number of linear waves, the superposition of which forms a choppy surface;

- circular frequency, amplitude and phase of every linear wave is determined; starting phase is assigned by a random number in the range of $0 . .2 \pi$;

-with the help of transfer function a time series of free surface elevation is converted into a time series of wave generator movement, which, in its turn, is converted into a time series of voltage, which is fed to the wave generator.

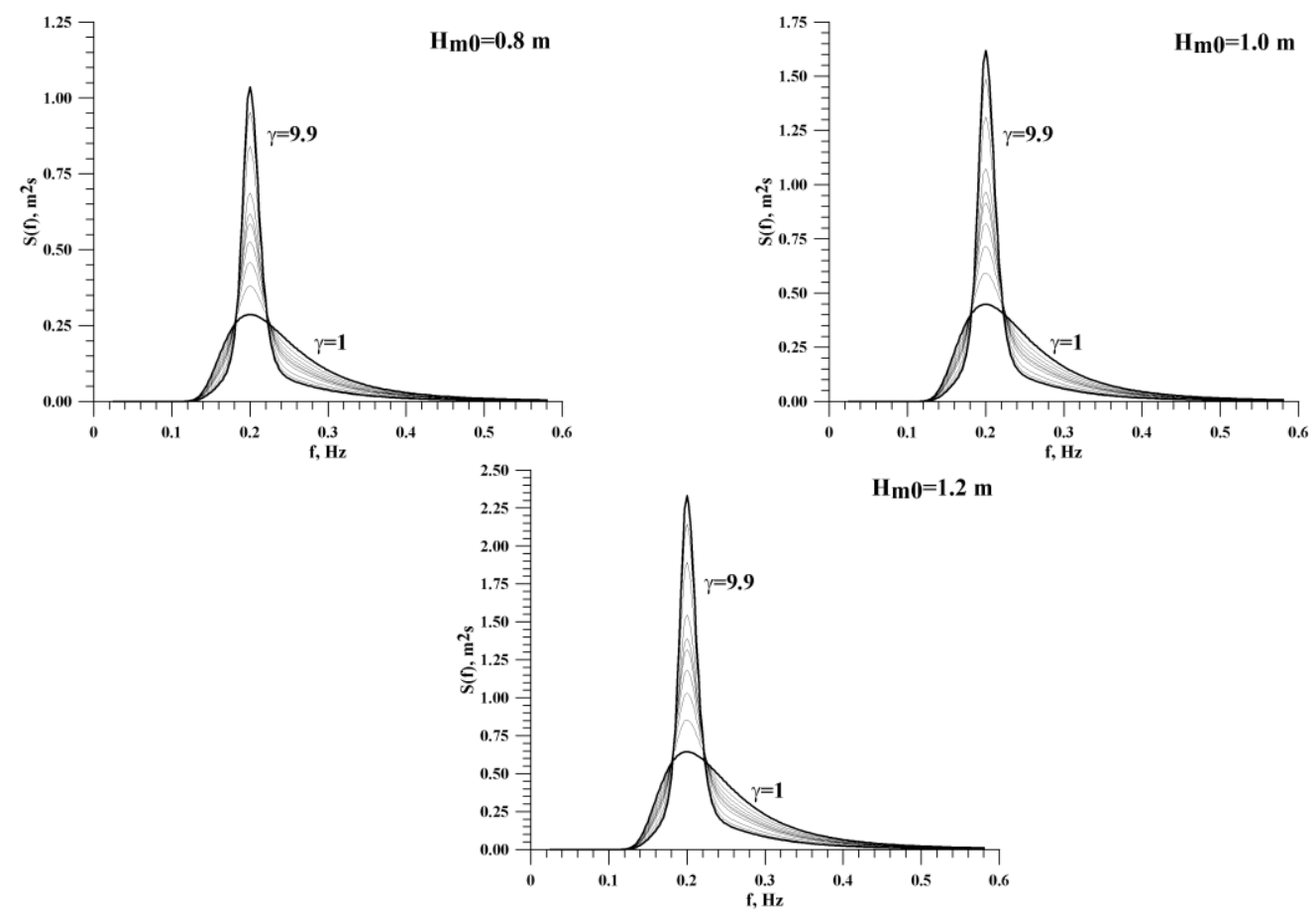

Figure 2. Spectral density of generated waves. For all series a period of maximum spectrum is $T_{p}=5$ sec.
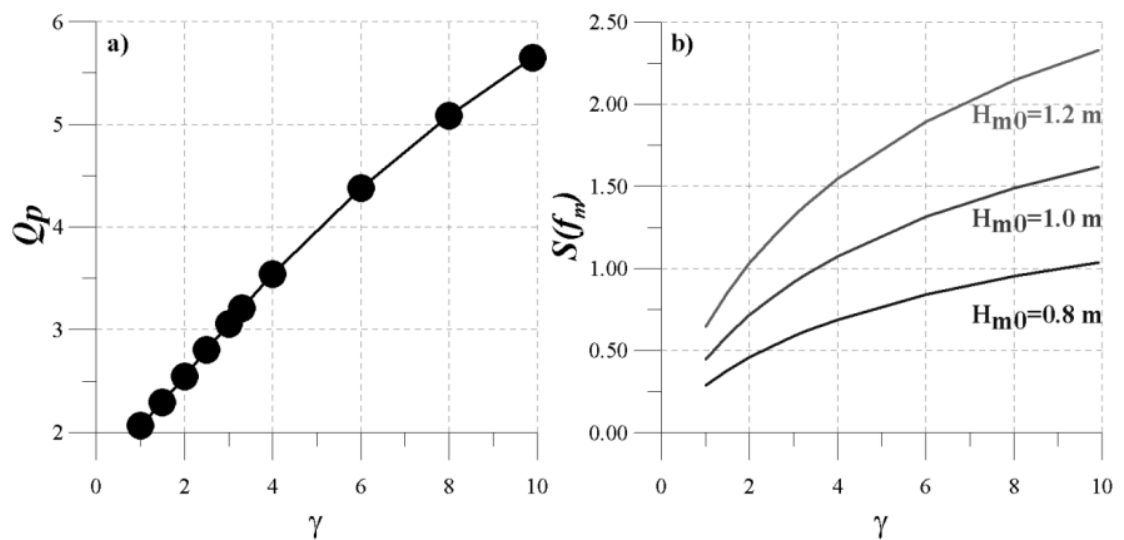

Figure 3. Spectral steepness parameter $Q_{p}$ vs peak enhancement coefficient $\gamma(a)$; maximum spectral density $S\left(f_{m}\right)$ vs peak enhancement coefficient $\gamma(b)$. 
When a wave is passing from the wave generator to the point of observation under the influence of nonlinear effects (bottom friction, peculiarities of bathymetry, surfing, etc) the waves are transformed. Spectral characteristics of waves change conformably. The research of such wave processes is possible, for example, with the use of a modern wave model based on a numerical solution of Naives - Stocks equation in approximation of Boussinesq. Test calculations of wave spectrum transformation in the Hannover'2008 experiment are presented in Fig. 4.
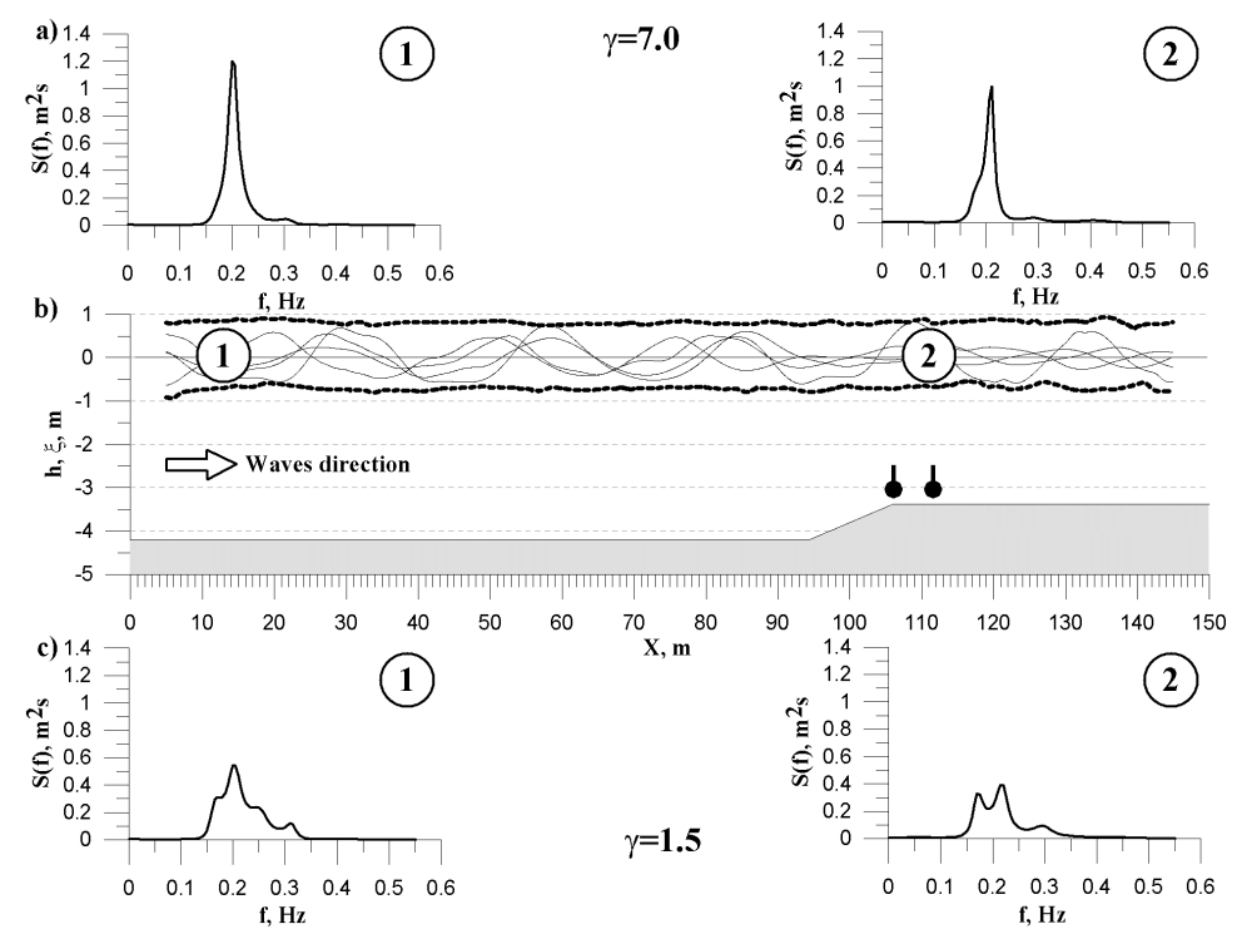

Figure 4. Transformation of wave spectrum in the Wave Channel.

The waves run from the wave generator $(X=0$, fig. $4, b)$ to the point of measurements (point 2 , fig. 4,b). Parameters of input spectra are: significant wave height is $\mathrm{H}_{\mathrm{m} 0}=1.0 \mathrm{~m}$, peak of the period is $\mathrm{T}_{\mathrm{p}}=5$ sec, $\gamma$ parameter is equal to 1.5, 7.0. Maximal (top dash line) and minimal (bottom dash line) values of elevation of free surface $\xi$ and, as an example, some instantaneous wave profiles are shown in Fig. 4, b. In general waves are transformed when they reach the front edge of submerged jut with partial collapse. When the $\gamma$ parameter grows and values of $\mathrm{H}_{\mathrm{m} 0}$ are invariable, the wave spectrum is more inconvertible one. It is connected with the fact that waves become more regular ones, and light tails in the distribution of the wave height are cut off. The chronograms of free surface elevation in the point of observation found by instrumental method afford to plot the experimental statistics of the distribution of the wave height and period under all assigned wave regimes. Calculated wave parameters under certain regimes are given in Table 1.

Here a more accurate definition is necessary. In the strict sense, both the wave height $\mathrm{H}_{\mathrm{m} 0}$, obtained as an integral of the wave process dispersion, and the height $\mathrm{H}_{1 / 3}$, calculated on the wave-by-wave analysis, are the different presentation of a significant wave height $\mathrm{H}_{\mathrm{s}} \cdot \mathrm{H}_{1 / 3}$ is a result of direct measurement, whereas $\mathrm{H}_{\mathrm{m} 0}$ is an assessed value. In conditions of deep water these two values practically concur. On the shallow water, as Thomson's and Vincent's investigations (1985) have shown, and particularly within the surf zone, they may differ for $10 \%$. Therefore values of $\mathrm{H}_{1 / 3}$ and $\mathrm{H}_{\mathrm{m} 0}$ in Table 1 will be different both on account of the wave transformation itself, and owing to their different determination. The uses of calculated H1/3 require more careful calibration of the model itself and it is possibly a goal of future investigations.

As it follows from Table 1, with the growth of $\gamma$ parameter and when $\mathrm{H}_{\mathrm{m} 0}$ approximations of JONSWAP wave spectrum are invariable, a significant wave height in $\mathrm{H}_{1 / 3}$ and a mean wave period $\mathrm{T}_{\text {mean }}$ increase too. The decrease of values of maximal wave periods $\mathrm{T}_{\max }$ is also observed, in general, waves become shorter and, therefore, steeper. 


\begin{tabular}{|c|c|c|c|c|c|c|c|c|}
\hline \multirow{3}{*}{\multicolumn{2}{|c|}{$\begin{array}{l}\text { Parameters } \\
\text { calculated on the } \\
\text { wave record }\end{array}$}} & \multicolumn{7}{|c|}{ Input parameters of a spectrum } \\
\hline & & \multicolumn{4}{|c|}{$\mathrm{H}_{\mathrm{m} 0}=1.0 \mathrm{~m}$} & \multicolumn{3}{|c|}{$\mathrm{H}_{\mathrm{m} 0}=1.2 \mathrm{~m}$} \\
\hline & & $\gamma=1.0$ & $\gamma=1.5$ & $\gamma=2.5$ & $\gamma=3.3$ & $\gamma=1.5$ & $\gamma=2.5$ & $\gamma=6.0$ \\
\hline Nun & er of waves & 811 & 798 & 782 & 774 & 735 & 676 & 627 \\
\hline \multirow{6}{*}{$\begin{array}{l}\text { Wave } \\
\text { height, m }\end{array}$} & $\mathrm{H}_{\max }$ & 1.60 & 1.52 & 1.84 & 1.77 & 1.78 & 1.79 & 1.93 \\
\hline & $\mathrm{H}_{\text {mean }}$ & 0.45 & 0.45 & 0.45 & 0.46 & 0.56 & 0.59 & 0.63 \\
\hline & $\mathrm{H}_{\text {median }}$ & 0.39 & 0.38 & 0.35 & 0.38 & 0.53 & 0.55 & 0.58 \\
\hline & First quartile (25\%) & 0.05 & 0.05 & 0.08 & 0.10 & 0.08 & 0.18 & 0.24 \\
\hline & Third quartile $(75 \%)$ & 0.75 & 0.75 & 0.74 & 0.76 & 0.90 & 0.91 & 0.97 \\
\hline & $\mathrm{H}_{1 / 3}$ & 0.88 & 0.90 & 0.94 & 0.92 & 1.11 & 1.11 & 1.17 \\
\hline \multirow{5}{*}{$\begin{array}{l}\text { Wave } \\
\text { period, } \\
\text { sec. }\end{array}$} & $\mathrm{T}_{\max }$ & 8.41 & 7.35 & 7.58 & 7.31 & 8.22 & 7.45 & 6.92 \\
\hline & $\mathrm{T}_{\text {mean }}$ & 2.49 & 2.57 & 2.61 & 2.60 & 2.77 & 2.98 & 3.22 \\
\hline & $\mathrm{T}_{\text {median }}$ & 2.51 & 2.65 & 2.82 & 2.73 & 2.88 & 3.23 & 3.65 \\
\hline & First quartile (25\%) & 0.77 & 0.78 & 0.73 & 0.78 & 1.02 & 1.08 & 1.38 \\
\hline & Third quartile $(75 \%)$ & 3.98 & 4.13 & 4.25 & 4.26 & 4.28 & 4.61 & 4.68 \\
\hline
\end{tabular}

\section{RESULTS AND DISCUSSION}

Peculiarities of bottom material suspending under waves with assigned spectral parameters mainly reveal themselves at a certain distance from the bottom. Calculated mean concentrations of suspended particles on the data of study with the help of turbidimeters, mechanical pumps and ABS are shown in Figure 5. The data were averaged according to observation series with duration about 20 minutes.
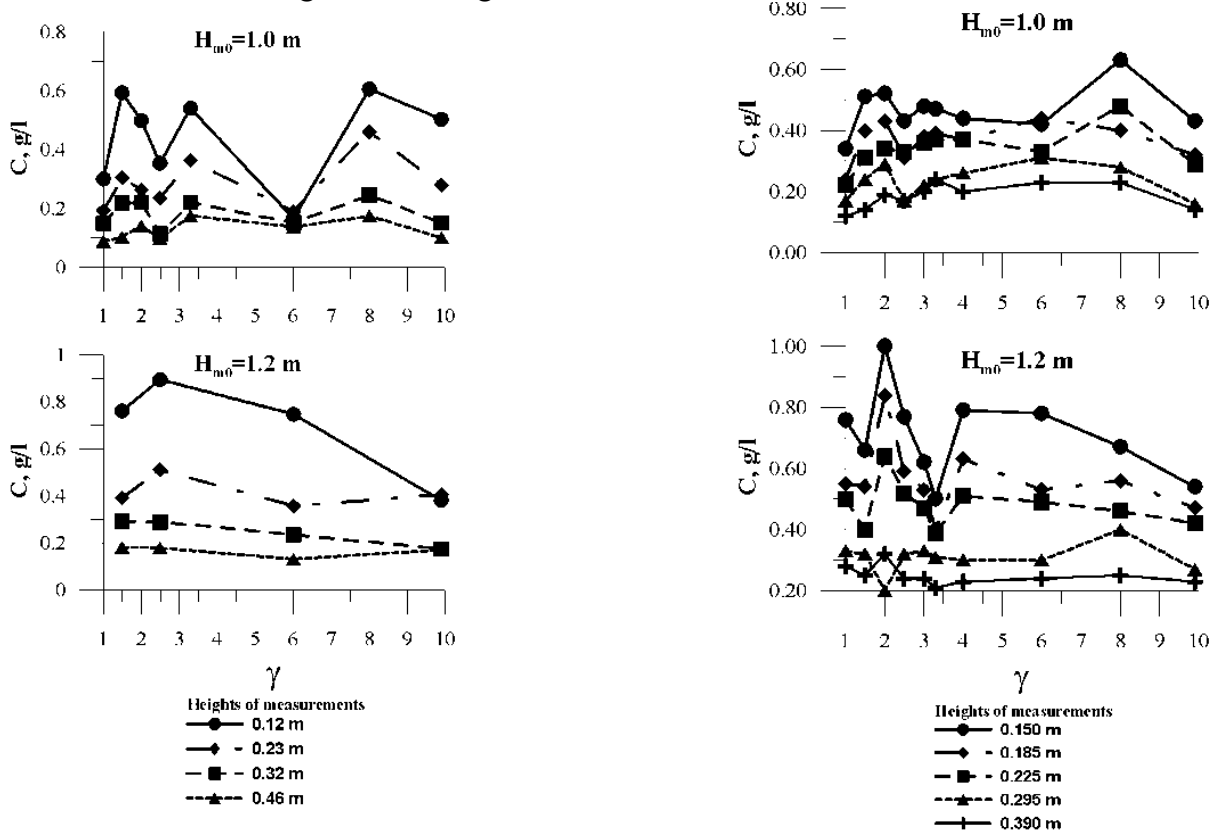

Turbidimeters

Pumps

Figure 5a. Mean values of suspended particle concentration at the measuring horizons with assigned wave parameters. Turbidimeters and pumps data. 

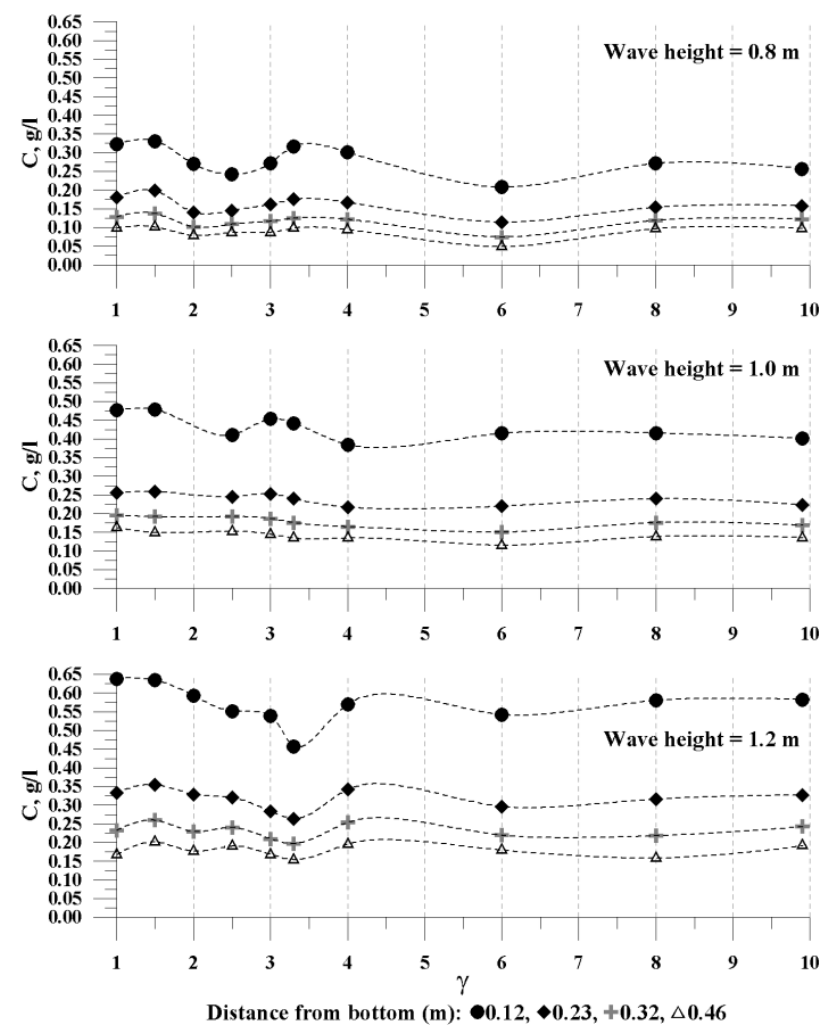

Figure 5b. Mean values of suspended particle concentration at the measuring horizons with assigned wave parameters. ABS data.

Regularities of suspending are controlled by a general energy of the process. In this respect the influence of the increase of significant wave height, and consequently, general energy of waves, on the process of bottom material entrainment and redistribution is larger than effects caused by the changes of interior structure of waves. Besides, when $\gamma$ parameter increases $\left(\mathrm{H}_{\mathrm{m} 0}\right.$ values keep to be invariable), a total amount of waves recorded in the point of observation decreases (table 1), and this certainly affects the dynamics of suspending.

Experimental data do not point to any evident tendency in the nature of the bottom material suspending with the increase of the peak enhancement factor. Nevertheless, a physical picture of suspension slightly changes with the growth of $\gamma$. It is well known that in the course of transformation low-frequency components appear in the spectrum of short waves. This can be explained by the intrawave nonlinear interaction, group wave structure, wave breaking. In the case of wave breaking the main factor of long-wave oscillations generation is the shift of line of breaking caused by the heterogeneity of the wave field.

As a matter of fact, $\gamma$ parameter to a certain extent characterizes the heterogeneity. Numeric tests on the transformation of the wave field show that when $\gamma$ decreases, the contribution of low-frequency components into the general energy of the process increases. In Figure 6 calculated normalized spectral densities of the surface waves are shown for the conditions of the Hanover wave channel; at the distance of 20 meters from the wave generator (Fig. 6a) and in the point of measurements (Fig. 6b). The parameters of initial spectrum are: $\mathrm{H}_{\mathrm{s}}=1.0 \mathrm{~m}, \mathrm{~T}_{\mathrm{p}}=5 \mathrm{~s}, \mathrm{~g}=1.5,9.9$. As is evident from Figure 6 , in the course of transformation the long-wave components with periods 20-30 s appear in the wave spectrum, which influence upon a general picture of suspension.

The suspended sediment concentration measured at the distance of $12 \mathrm{~cm}$ above the bottom is taken as an example. The parameters of the initial spectrum are the following: $\mathrm{H}_{\mathrm{s}}=1.0 \mathrm{~m}, \mathrm{~T}_{\mathrm{p}}=5 \mathrm{~s}, \mathrm{~g}$ $=1.5,4.0,9.9$. High-frequency components were filtered out in input series, these series were also saved from trend components. Spectral densities of fluctuations of suspended material concentration in low-frequency range of changeability are also shown in Figure 7. According to preliminary estimation when the width of the spectrum increases (and respectively $\gamma$ parameter of JONSWAP spectrum decreases) the contribution of low-frequency fluctuations into a general energy picture of suspension grows too (and the total energy is permanent for all three cases, and is proportional to the square of the wave height). 


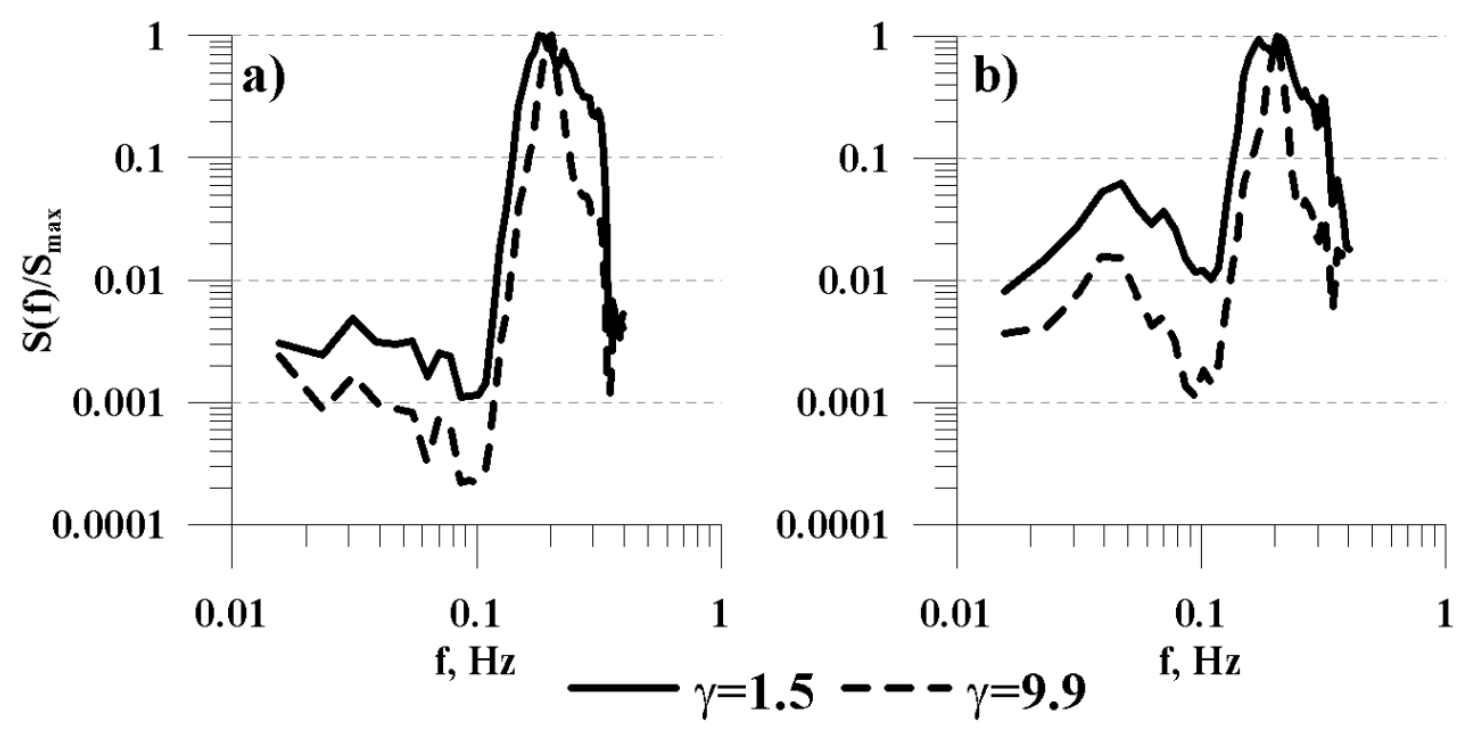

Figure 6. Normalized spectral density of the surface waves.

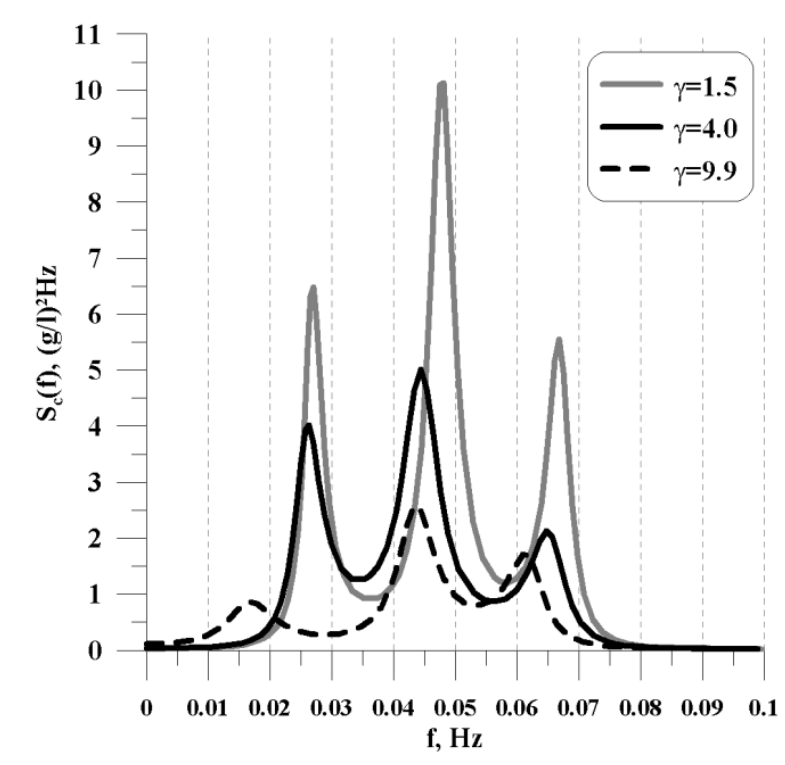

Figure 7. Spectral density of fluctuations of the suspended sediment concentration.

\section{SUMMARY}

Experimental investigations of complex and multifactorial processes of suspending require a special attention to the questions of the experiment planning and realization. It relates both to the choice of research instruments and methods of the result processing. For example, statistics of wave height obtained on the same wave record by different methods (determination of wave height on the crests, troughs, intersection of zero line) may differ for $10-15 \%$. The way out of such a situation is the accumulation of database by means of further experimental investigations supplemented with results of effective mathematical modeling.

Further researches:

-performance of additional chute experiments with the purpose of obtaining of statistically significant dependence of the parameters of suspension on the wave structure;

-estimation of the low-frequency fluctuations contribution into the process of the bottom sediment suspending. 


\section{ACKNOWLEDGMENTS}

Researches were accomplished under the support of the Russian Foundation for Basic Research, grants 08-05-00088, 08-05-91851.

\section{REFERENCES}

Grüne J., Kosyan R., Oumeraci H., Podymov I., Schmidt-Koppenhagen R., Vincent C. 2007. Largescale laboratory modelling of suspended sand concentration fluctuations under irregular waves, Proc. of the Coastal Sediments'07, ASCE.

Hasselmann, K., Barnett, T., Bouws, E., Carlson, H., Cartwright, D., Enke, P., Ewing, J., Gienapp, H., Hasselmann, D., Kruseman, P., Meerburg, A., Müller, P., Olbers, D., Richter, K., Sell, W. and Walden, H. 1973. Measurements of wind-wave growth and swell decay during the Joint North Sea Wave Project (JONSWAP), Dtsch. Hydrogr. Z. Suppl. A, 8:-95.

Liu, Z. and Frigaard, P. 2001. Generation and analysis of random waves, Aalborg Universitet, $76 \mathrm{p}$.

Thompson, E. and Vincent, C. 1985. Significant wave height for shallow water design, ASCE Jour. Waterw., Port, Coastal and Ocean Engr., Vol. 111, pp. 828-842. 